\title{
Should CSR Give Atheists Epistemic Assurance? On BeER-Goggles, BFFs, AND SKEPTICISM REgARDING RELIGIOUS BELIEFS
}

\author{
JuSTIN L. BARRETT AND IAN M. CHURCH \\ Fuller GRADUATE SCHOOL OF PSyChOlOGY \\ (Published IN THE Monist: 2013, vOL. 96, NO. 3, PP. 311-324)
}

Recent work in cognitive science of religion (CSR) is beginning to converge on a very interesting thesis - that, given the ordinary features of human minds operating in typical human environments, we are naturally disposed to believe in the existence of gods, among other religious ideas (e.g., see Atran 2002; Barrett 2004; Barrett 2012; Bering 2011; Boyer 2001; Guthrie 1993; McCauley 2011; Pyysiäinen 2004; Pyysiäinen 2009). In this paper, we explore whether such a discovery ultimately helps or hurts the atheist position - whether, for example, it lends credence to atheism by explaining away religious belief or whether it actually strengthens some already powerful arguments against atheism in the relevant philosophical literature. We argue that the recent discoveries of CSR hurt, not help, the atheist position - that CSR, if anything, should not give atheists epistemic assurance.

Imagine you are a hot-blooded single person who has gone to a popular nightspot with a group of friends. You've been there some thirty minutes and come to the disappointing conclusion that the clientele of this club isn't terribly attractive. Just as that thought crosses your mind, your companions begin commenting just the opposite, that the place is loaded with hotties. Naturally, you feel puzzled. Perhaps, given that the consensus is against you, you start doubting your own conclusion. Maybe there is something wrong with your judgment. Maybe your eyes aren't working right or your taste is out of step with your peers. 
Such is the situation for the atheist living today in the vast majority of cultural contexts in the world. About 9 out of every 10 people look around their life and arrive at the conclusion that there is at least one god, but the atheist looks around and reaches the opposite conclusion. The atheist may find this disconcerting: Why do I see the big metaphysical questions so differently from most people? Is there something wrong with my judgment?

Let's return to the nightclub. You've made sure your contact lenses are clean and well placed, you've re-inspected the human exhibits and you still find yourself underwhelmed. The disconcerting question arises: Why is your judgment so different than your companions'? Then it dawns on you. As you are the responsible designated driver, you have had no alcohol, only two tumblers of cranberry juice. Your companions, however, have already downed several drinks and, hence, are, to use a popular idiom, "wearing their beer goggles." That explains it! When wearing beer goggles, when intoxicated, vastly more people seem attractive. Your friends are misperceiving reality because something is interfering with the reliability of their relevant beliefforming faculties (BFFs), and so you can take new comfort in your divergent perspective on the facts of the matter.

Back to atheism: Have observations from CSR revealed that most people are wearing the equivalent of beer goggles concerning the existence of one or more gods? If so, should atheists be comforted by this observation and fortified in their conviction that no gods exist?

CSR and related evolutionary approaches have begun to converge upon the thesis that because of the ordinary features of human minds operating in typical human environments, making sense of and acting in the world, humans are naturally disposed to believe in gods among other religious ideas (e.g., see Atran 2002; Barrett 2011; Bering 2011; Boyer 2001; McCauley 
2011; Pyysiäinen 2009). ${ }^{1}$ These natural cognitive dispositions help account for widespread recurrence of recognizably similar religious beliefs and practices. A full description of even representative accounts is beyond the scope of this essay, but a few points are important for the present discussion. First, the claim is that naturally and ordinarily people are attracted to beliefs regarding the existence of one or more gods, something like a soul, the existence of some sort of afterlife, etc. You do not need unusual abilities, experiences, or pathology to find yourself drawn to such beliefs. Religious beliefs are natural (Bloom, 2007). Second, the widespread view of CSR scholars is that the faculties that incline humans toward religious beliefs are part of the general conceptual toolkit for negotiating life as a human and not some special religion-specific faculty or "god spot" in the brain (Barrett 2004; Bering 2011; Boyer 2001; Schjødt et al. 2009). For instance, among other faculties, the CSR literature repeatedly emphasizes the importance of normally functioning human faculties that concern identifying, understanding, and interacting with minded beings or persons, including the 'theory of mind' system (e.g., Barrett 2004; Bering 2011; Guthrie 2001; McCauley 2011; McCauley and Lawson 2002). Third, CSR provides only partial and probabilistic explanations of religious belief. That is, the cognitive dynamics that encourage religious belief do not compel people to hold fully developed ideas about the Christian God or any other. People may feel an intuitive pull toward certain religious ideas but reflectively embrace, modify, or reject such intuitions. For the sake of this essay, let us presume that these CSR scholars are on the right track.

\footnotetext{
${ }^{1}$ It may be that some exceptional cultural environments serve to modify or override these tendencies but the standard claim is that the tendencies are generally present in humans regardless of time and place. Bering (2011) argues explicitly that atheists often experience dissonance and consistency problems precisely because of these natural conceptual tendencies.
} 
With these observations in mind, then, should CSR give atheists comfort and assurance in their belief that there are no gods? At first blush, it appears so. The atheist is in a similar situation as the person in the nightclub: a majority of others hold a particular belief that seems to be false, but their holding of that belief seems to be causally accounted for by a problem with their belief-forming faculties (BFFs). In the nightspot the BFFs are impaired by alcohol, and in the human population at large, the BFFs are biased toward belief in the existence of at least one god. The atheist, so the story goes, has managed to override these natural intuitions through unusual cleverness, education, or enculturation. Or perhaps the atheist's cognitive faculties aren't tuned in quite the same way as the theist's, but this alternative tuning is relatively rare. In either or both cases, it appears that any discomfort felt over seeing the world differently from so many others may now be discarded (assuming the atheist has good grounds for his atheism). If, as the atheist supposes, there are no gods, the majority of humans naturally have BFFs that encourage them toward false beliefs. Their BFFs are unreliable with respect to these metaphysical commitments.

Note, however, that this argument need not pose a worry for theism. A defender of theism may simply reply that theists BFFs are appropriately tuned, perhaps because a cosmos-designing god wanted it that way. Similarly, your friends at the nightclub may have additional reasons for regarding the place as full of attractive singles (e.g., it is regularly ranked as the top club in the region for attractive people, ugly people are turned away by bouncers, etc.) and/or may regard some alcoholic lubrication as required for enhancing one's attractiveness-discernment abilities. In either case, when you tell them they are wrong about the proportion of hotties because of their consumed alcohol, they are under no obligation to change their beliefs. The prior commitments of the theist may lead to an entirely different construal of the claims of CSR. Nevertheless, 
given the prior commitments of the atheist, CSR appears to provide grounds to place aside any niggling concerns generated by being in the minority on this metaphysical appraisal.

Perhaps, however, the assurance CSR provides atheists is less certain than it first seems. Assurance in the nightclub example comes from discovering that the majority opinion has been swayed by "beer goggles". But are the natural dispositions toward belief in at least one god relevantly analogous to beer goggles? Of course, the theist will think not, but does the atheist have reason to think the situation with the beer goggles isn't relevantly analogous? One concern may be that in the case of consuming alcohol we have independent reason to suspect that perception and judgment are impaired and so when it is applied to beliefs about the relative attractiveness of people, we can be pretty comfortable with the belief that lots of alcohol consumed counts against the reliability of the relevant BFFs. In the case of religious beliefs and the factors CSR identifies, do we have independent reason to suspect that BFFs are unreliable? In order to answer this, we need a closer scrutiny of the sorts of beliefs these various cognitive subsystems produce and at what degree of accuracy (if such accuracy is not inscrutable). Barring such an analysis, it may be imprudent to assume that the factors CSR has posited as relevant for religious belief formation are relevantly analogous to beer goggles and beliefs about attractiveness.

But suppose it can be conclusively shown that human minds are naturally tuned toward false positives regarding beliefs in the existence of gods as some in CSR have suggested (e.g. Guthrie 1993; Guthrie 2001), comparable to alcohol consumption leading to false positives regarding attractiveness of others. ${ }^{2}$ In the nightclub, you have reason to suspect that your comrades are over-detecting attractive people, but it does not follow that you have rightly

${ }^{2}$ Michael Murray (2009) has raised serious doubts regarding the possibility of such a demonstration regarding our religious belief-forming faculties without question-begging. 
appraised the situation either. Maybe an as yet undiscovered consequence of drinking cranberry juice is that it makes you regard people as less attractive than you would otherwise. So, your friends are being too permissive in their judgments and you are being too conservative, failing to accurately detect attractiveness. Perhaps the truth lies in the middle: you are right that your friends are finding some people attractive who are not, but you are failing to find people attractive who are. Likewise, maybe it is the case that the cognitive faculties that encourage beliefs in gods are tuned in most people to over-detect gods, detecting them in situations when they are not present, detecting signs of their activity that are illusory, and so on. But it doesn't follow that the atheist's BFFs are tuned correctly regarding such metaphysical beliefs. They could err in the opposite direction.

Then again, suppose the atheist's prior commitments are such that it is improbable that his own belief-forming faculties are too conservative with regard to believing in gods. To them it will seem as though the vast majority of humans have cognitive faculties that are unreliable with regards to metaphysical beliefs about gods, souls, the afterlife, and so on. ${ }^{3}$ Surely, then, the findings from CSR give some assurance to such an atheist.

This raises the issue of the reliability of garden-variety belief-forming faculties generally. Recall that CSR cites ordinary cognition - the mechanisms for making sense of the natural and social world — not special religion-specific faculties as one important cause for people's religious beliefs. Religious people may be concerned that these faculties, given their generality, do not deliver the particular theological convictions of their tradition alone, but only point people in the right direction. Atheists, however, regard the outputs of these faculties as not vague but wrong. These faculties are not imprecise, they are unreliable. Religious beliefs are not the only beliefs

${ }^{3}$ This appears to be Jesse Bering's position (2011). 
these faculties form, however. If they are unreliable when forming metaphysical beliefs about the existence of gods, souls, and the afterlife, are they reliable to deliver true beliefs regarding the features and causal properties of the natural world, the social world, human minds, and moral realities? An argument may be constructed as follows, in which the natural, ordinary beliefforming faculties identified by CSR are represented by CSR-BFFs.

(1) There are no gods, souls, and afterlife.

(2) CSR-BFFs typically produce beliefs in gods, souls, and the afterlife.

(3) Hence, CSR-BFFs typically produce false beliefs.

(4) BFFs that typically produce false beliefs are unreliable.

(5) Hence, CSR-BFFs are unreliable.

(6) Beliefs formed by unreliable faculties lack warrant.

(7) CSR-BFFs produce beliefs about human minds (including conscious beliefs, desires, emotions, and their relationship to actions), the causal properties of the natural world, and so on.

(8) These beliefs (from (7 and 5)) lack warrant.

Recognizing that ordinary cognitive faculties identified by CSR lead to such widespread, systematic formation of false beliefs, atheists appear to be compelled to at least weaken their commitment to other sorts of beliefs independent of religion. Exactly which beliefs are suspect depends upon the range of (7) above, just which beliefs are formed by the same mechanisms that support religious beliefs; however, an exhaustive specification would be largely speculative given the current state of CSR. Nevertheless, the general point is that regarding as reliable the 
BFFs that produce religious beliefs has negative epistemic implications for many other, nonreligious beliefs. ${ }^{4}$

One possible objection to this argument is to question (3): just because the faculties CSR has identified as relevant to religion are unreliable in the contexts in which they form religious beliefs, it does not follow that they are generally unreliable or unreliable in non-religious contexts. Michael Murray has addressed this objection elsewhere (2009). Murray argues that without being able to specify (a) that the conditions under which religious beliefs are formed are importantly different from those for non-religious beliefs, and (b) that the faculties in question can be shown to have better reliability in one set of contexts as opposed to the others, then the objection appears to be no more than special pleading. It does not appear that either of these two conditions will be soon met. Cleanly marking off the conditions under which religious beliefs are formed and held by the BFFs from the conditions for non-religious beliefs simply cannot be done. For instance, theists believe in God in the same cognitive environments in which they believe in other minds. ${ }^{5}$ Religious thought and action has been co-extensive with mundane human life for most of human history, suggesting that the conditions of religious belief formation and maintenance may be indistinguishable from those of most other human beliefs.

A more promising way forward for the atheist, however, may be to simply concede to the claim that the cognitive faculties in question appear to be unreliable and any beliefs formed with their encouragement require special scrutiny. Perhaps this leads to skepticism regarding the

\footnotetext{
${ }^{4}$ And to be sure, the problem isn't just that CSR-BFFs occasionally lead to false beliefs according to atheism. Many cognitive faculties (e.g. vision, long-term memory, etc.) will occasionally get matters wrong while still being generally aimed at truth. The problem with CSR-BFFs is that, according to atheism, they are systematically false, in no way aimed at truth.

${ }^{5}$ See Plantinga 1967.
} 
existence of minds and other such beliefs; so be it. The exact range of the skepticism may be uncertain, but perhaps that is a fair price to pay for confident atheism.

Skepticism of this sort may be acceptable to some atheists, but probably not to those who presume to have arrived at their atheism because of the findings and theories of modern science. To such an atheist, the findings of CSR have demonstrated that important human BFFs are unreliable for forming true beliefs in the vast majority of humans as detailed in (1) through (5) above. Which means that the winnowing processes of natural selection have endowed most humans with unreliable BFFs, apparently at no important cost to fitness. Does such an atheist, then, have good reason to trust his BFFs generally? ${ }^{6}$ After all, apparently it is not just possible but common to have cognitive faculties that are systematically pointed toward false beliefs and still enjoy good fitness. If this were the case, natural selection cannot be counted on to eliminate unreliable BFFs.

What assurance then does one have that one's BFFs are reliable? And if they cannot be trusted as reliable, then their deliverances, including atheism and CSR explanations themselves, should be regarded as arising from an unreliable source, and hence, not be trusted. ${ }^{7}$ But then the conjunction of atheism and CSR appears to be self-defeating. That is, atheism plus the accounts from CSR provide reason to doubt the belief-forming faculties relevant for forming beliefs about atheism and about CSR. Adding CSR to atheism (at least of this scientific sort), should not assure the atheist, but actually provides evidence against atheism.

Adaptationist accounts of religion make the difficulty even worse. Their conjunction with atheism does not merely allow for the possibility of non-truth-aimed BFFs to survive

\footnotetext{
${ }^{6}$ Or at least those beliefs that concern metaphysical and other abstract considerations such as belief in the existence of moral truths, other minds, purpose in life, etc.

${ }^{7}$ A similar argument is developed by Clark and Barrett (2011).
} 
natural selection, it suggests that some false belief systems and subsequent behaviors are actually encouraged by natural selection. Some false beliefs lead to better fitness. If that is so, why should we trust our BFFs to supply true beliefs?

But how is this different from the general problem posed by false positives - scenarios where cognitive faculties, which are typically veritic, nevertheless occasionally "cry wolf," indicating certain conditions when no such indications obtain? For example, cognitive scientists have long since known that the faculties responsible for agent-detection are overly sensitive, and as such we are far more likely to wrongly detect a monster under our bed, say, than we are to leave an agent undetected when actually presented with one. ${ }^{8}$ Why aren't the recent deliverances of CSR roughly analogous to false positives? Why, for example, can't the atheist respond by saying that our cognitive faculties, while typically veritic, nevertheless are "crying wolf" when it comes to religious beliefs, in the same way our cognitive faculties might "cry wolf" regarding an imagined monster under the bed? If religious belief is roughly analogous to a false positive for the atheist, then no uniquely troubling skeptical conclusion follows. If religious belief is roughly analogous to a false positive for the atheist, then either (i) no substantial skeptical conclusion follows (because false positives aren't problematic) or (ii) the theist's position is no better off (because presumably the theist's position is just as afflicted by false positives).

${ }^{8}$ Or do we know that these faculties produce false positives more than false negatives? It certainly appears that way (we have all experienced times in which we thought someone was present in error) but perhaps these occasions are vastly outnumbered by our failures to detect agents and agency all around us. To judge the accuracy of a device, a sure standard is required against which to judge the device's measurements, and it is not at all clear what the sure standard for the presence or absence of agents and agency is. If it is true that the world is populated by hard-to-detect spirits, then we may be failing to detect agents all the time. Are humans really agents? Ants? Computers? 
But the problem posed by CSR for atheism is markedly different from a false positive. In false positive scenarios, our cognitive faculties are generally aimed at truth; this simply isn't the case for religious beliefs from the atheist's perspective. Consider once again the false positives generated by our overly sensitive agent-detection faculties. Even though we occasionally wrongly detect a monster under the bed, our agent-detection faculties might nevertheless still be generally aimed in the right direction (at truth) and extremely reliable. In the case of distinctly religious beliefs, however, it is difficult to see how the atheist could see them as somehow aimed in the right direction or in any way indicative of a more general and reliable cognitive faculty. For the atheist, the cognitive faculties that naturally produce distinctly religious belief are not aimed at truth, they are presumably simply aimed at falsehoods. And as such, the problem posed by CSR for atheism, with its skeptical conclusions, is unique.

But even if the recent deliverances of CSR pose a unique problem, is it really of particular relevance to atheism or does it extend to most theisms as well? After all, it seems as though given the dizzying array of religious beliefs, philosophies, and practices in the world, any given theist position would be crippled with a very similar problem. Atheism, it seems, runs into skeptical worries because it forces us to question the reliability of our cognitive faculties because it deems false the vast majority (if not all) of our naturally formed religious beliefs. But doesn't a very similar argument apply to most stripes of theism? For example, doesn't Christianity, say, also force us to question the reliability of our cognitive faculties and lead to skeptical worries? ${ }^{9}$ After all, prima facie Christianity (in many stripes) seems to entail that the vast majority (though not all) of our religious beliefs are false (i.e. Christianity might seem to entail that the core beliefs of Islam, Hinduism, various forms of paganism, etc. are false). No doubt, the argument

\footnotetext{
${ }^{9}$ Murray took up this concern similarly elsewhere (2009) and concluded, as we do, that such an argument does not pose a formidable problem for theism. See also Clark and Barrett 2011.
} 
against any such stripe of theism seems weaker - entailing only that most (though not all) of our religious beliefs are false - but only just. Perhaps, then, the recent deliverances of CSR don't push us to theism; perhaps they simply push us toward radical skepticism. ${ }^{10}$ And if the findings of CSR alone pushes us to radical skepticism, such that we will be skeptical even of CSR, it is self-defeating and itself warranting of rejection.

No such skeptical conclusions actually follow, however, from the recent deliverances of CSR for the theist. After all, the findings of CSR do not suggest that specific religious beliefs, theologies, philosophies, and practices are the natural product of our cognitive faculties; it is not as if our cognitive faculties are geared toward specific beliefs in infant baptism, supralapsarianism, annihilationism, or anything of the like. Rather, the recent findings of CSR simply suggest that our cognitive faculties are naturally geared toward religious beliefs in general. And as such, the theist qua her theism can affirm that the general and natural religious leanings of our cognitive faculties as veritic - dissolving any skeptical worries regarding the reliability of our faculties. ${ }^{11}$ The atheist qua his atheism, however, can make no such move; for the atheist, the general and natural religious leanings of our cognitive faculties are straightforwardly unreliable and not aimed at truth. And it is this state of affairs that produces skeptical worries regarding the general reliability of our cognitive faculties for atheism but not for theism. The recent findings of CSR alone do not push us toward radical skepticism; it is only

\footnotetext{
${ }^{10}$ We are assuming here that atheism and theism are the only serious research programs on offer - such that the rejection of one typically leads to the acceptance of the other. In theory, someone could espouse some form of non-theistic supernaturalism that is incompatible with atheism, but we won't worry about any such tertium quid.

${ }^{11}$ Of course, religious pluralism and the naturalness of religious belief make perfect sense from many theist perspectives as well. For example, Christian theology regarding general and special revelation and the fall of mankind would almost predict the state of affairs prescribed by the findings of CSR.
} 
when those findings are coupled with atheism that such problems arise. And as such, given that we should not reject the recent deliverances of CSR, it is atheism that looks self-defeating and warranting of rejection.

So the growing consensus within CSR research that humans are naturally disposed to believe in gods among other religious ideas does not seem to give assurance to atheists; indeed, to the contrary, it seems to offer a defeater for atheism - posing unique skeptical worries to the atheist position. But just how radical are these skeptical worries? If the atheist can show that the skeptical worries generated by the findings of CSR are only localized within certain domains or are otherwise bearable, then even if CSR does not give atheist assurance perhaps any defeater it generates will be relatively weak - potentially leaving the atheist with the opportunity of arguing that atheism is, all things considered, the more viable position. After all, even if the recent deliverances of CSR give the atheist reason to question the reliability of a broad set of cognitive faculties, perhaps this is mostly limited to our cognizing about abstract concepts or various debates in metaphysics. ${ }^{12}$ What is more, even if we have a worry regarding the reliability of certain broad cognitive faculties, why think that such skepticism extends to, say, our everyday auditory beliefs or our everyday visual beliefs? Even if we doubt the reliability of our cognitive faculties when it comes to a relatively limited range of topics in metaphysics, why should this give us any reason to doubt that " $p$ is red" when $p$ appears to us redly, say? Maybe the skepticism generated by CSR for the atheist isn't all that radical; the atheist might see it as an unfortunate or even regrettable discovery, but perhaps it is not ultimately fatal for his position.

Of course, any systematic doubt regarding the reliability of any broad set of cognitive faculties is a tough pill to swallow. As we've already noted, the skepticism pertains not just to

${ }^{12}$ After all, skepticism regarding such topics has a long and illustrious history. See Berkeley 1710; Hume 1748. 
some isolated faculty responsible for religious beliefs, it pertains to our overall conceptual toolkit for negotiating life as a human - and this is a conclusion which, at the very least, many folks (including scientific realists) will find quite unacceptable. ${ }^{13}$ Even so, the skepticism generated by the recent deliverances of CSR might be seen as emblematic of a more comprehensive and far more serious worry for atheism - a worry that is sometimes called "Darwin's doubt." Consider the following quotes from Friedrich Nietzsche and Charles Darwin, respectively:

It is unfair to Descartes to call his appeal to God's credibility frivolous. Indeed, only if we assume a God who is morally our like can "truth" and the search for truth be at all something meaningful and promising of success. This God left aside, the question is permitted whether being deceived is not one of the conditions of life. (Nietzsche 2003, 26) ${ }^{14}$

Would any one trust in the convictions of a monkey's mind, if there are any convictions in such a mind? (Darwin 1881)

To put it roughly, Darwin's doubt is the worry that if there is no God, if the human mind is merely a product of evolution (without the input of a benevolent, designing God), "survival of the fittest" may only loosely track truth - that the telos of survival bears no significant relationship to the telos of truth. In his recent book, Where the Conflict Really Lies (2011), Alvin Plantinga helpfully spells out Darwin's doubt in a bit more detail:

\footnotetext{
13 At the very least, such skepticism would (or at least should) foster a healthy dose of intellectual humility amongst many of the most vocal, militant atheists of our day.

${ }^{14}$ Also quoted in Plantinga and Tooley 2008, 30.
} 
Here the idea of conditional probability will be useful...The condition probability of one proposition $p$ on another proposition $q$ is the probability that $p$ is true given that, on the condition that, $q$ is true....With this notion of conditional probability in hand, we can put Darwin's doubt as follows: the conditional probability that our cognitive faculties are reliable, given naturalism together with the proposition that we have come to be by way of evolution, is low. (Plantinga 2011,317)

In short, Darwin's doubt is the worry that naturalistic evolution, hallmark of the most prominent and most vocal brands of atheism, fuels radical skepticism - that atheism (of this sort) "is committed to the sort of deep and debilitating skepticism according to which he can't trust his cognitive faculties to furnish him with mainly true beliefs," posing a "defeater for whatever he believes," including his commitment to naturalistic atheism (Plantinga and Tooley 2008, 1). This is a worry that has been discussed and explored by philosophers of religion for quite some time ${ }^{15}$ Many such arguments, however, trade on thought experiments and armchair undertakings to lend credence to Darwin's doubt and the conclusion that (naturalistic) atheism leads to various forms of radical and untenable skepticism. And even though such arguments are often powerful and cogent, they lack a certain empirical punch - work done in the armchair is often all too susceptible to work done by other people in other armchairs. What the recent deliverances of CSR do, however, is give the theist concrete empirical data in support of Darwin's doubt concrete empirical data which suggests that if atheism is true a broad set of cognitive faculties, faculties which are part of our basic overall conceptual toolkit for negotiating life as a human,

\footnotetext{
${ }^{15}$ See, for example, Attfield 2010; Littmann 2011; Plantinga 1993; Plantinga 2000; Plantinga and Tooley 2008; Plantinga 2011.
} 
are hopelessly unreliable. And even if the findings of CSR do not cast direct doubt on beliefs formed by auditory or visual faculties, say, the credence they lend to the far more extensive and insidious worry of Darwin's doubt does.

Has the cognitive science of religion (CSR) given us reason to think that the belief forming faculties (BFFs) that encourage belief in at least one god (among other religious beliefs) are like "wearing beer goggles" - - leading to a misunderstanding of what is really there? We have argued that the relevant BFFs are importantly disanalogous from beer goggles. First, the reliability of these mechanisms cannot be independently determined in the relevant respects. More importantly, unlike when sobering up, these BFFs are always with us and are alleged to be important for forming a broad range of non-religious beliefs, as well. If skepticism with regard to their religious outputs is merited, then so too would be a serious degree of skepticism regarding many common beliefs. Supposing there are no gods, it appears evolution has endowed us with BFFs that are unreliable to deliver true beliefs. If that is right, on what grounds do we trust our BFFs at all, including when they provide us with beliefs about CSR or concerning the (non)existence of gods? Rather than give the doubter assurance that there are in fact no hotties in the nightclub, we find that the recent deliverances of CSR regarding the naturalness of religious beliefs and ideas seems to pose a worrying defeater for the atheist position - pushing the atheist toward radical skepticism. ${ }^{16}$

\footnotetext{
${ }^{16}$ The authors thank Robert Audi, Kelly James Clark, Tom Crisp, Adam Green, Myron Penner, and Matt Van Cleave for comments and suggestions. This work was supported in part by a grant from the John Templeton Foundation.
} 


\section{Works Cited}

Atran, Scott. 2002. In Gods We Trust: The evolutionary landscape of religion. Oxford: Oxford University Press.

Attfield, Robin. 2010. "Darwin's Doubt, Non-Deterministic Darwinism and the Cognitive Science of Religion.” Philosophy 85 (04): 465-483. doi:10.1017/S0031819110000422.

Barrett, 2004. Why would anyone believe in God? Lanham, MD: AltaMira Press.

- 2011. Cognitive Science, Religion, and Theology: From Human Minds to Divine Minds. West Conshohoken, PA: Templeton Press.

—. 2012. Born Believers: The Science of Children's Religious Beliefs. New York: The Free Press.

Bering, Jesse M. 2011. The Belief Instinct: The Psychology of Souls, Destiny, and the Meaning of Life. New York: W. W. Norton and Company.

Berkeley, George. 1710. A Treatise Concerning the Principles of Human Knowledge.

Bloom, Paul. 2007. "Religion is natural." Developmental Science 10: 147-151.

Boyer, Pascal. 2001. Religion Explained: The Evolutionary Origins of Religious Thought. New York: Basic Books.

Clark, Kelly James and Justin L. Barrett. 2011. "Reidian Epistemology and the Cognitive Science of Religion." Journal of the American Academy of Religion 79 (3): 639-675

Darwin, Charles. 1881. Darwin to Graham, William. July 3. http://www.darwinproject.ac.uk/darwinletters/calendar/entry-13230.html.

Guthrie, Stewart E. 1993. Faces in the Clouds: A new theory of religion. New York: Oxford University Press. 
—. 2001. "Why gods? A cognitive theory." In J. Andresen (ed.), Religion in Mind: Cognitive Perspectives on Religious Belief, Ritual, and Experience, pp. 94-111. Cambridge: Cambridge.

Hume, David. 1748. An Enquiry Concerning Human Understanding.

Littmann, Greg. 2011. "Darwin's Doubt Defended: Why Evolution Supports Skepticism." Philosophical Papers 40 (1): 81-103. doi:10.1080/05568641.2011.560028.

McCauley, Robert N. 2011. Why Religion Is Natural and Science Is Not. New York: Oxford University Press.

McCauley, Robert N., and E. Thomas Lawson. 2002. Bringing Ritual to Mind: Psychological Foundations of Cultural Forms. Cambridge: Cambridge University Press.

Murray, Michael J. 2009. "Scientific Explanations of Religion and the Justification of Religious Belief." In J. Schloss \& M. Murray (eds.) The Believing Primate: Scientific, Philosophical, and Theological Perspectives on the Evolution of Religion, pp. 168-178. New York: Oxford University Press.

Nietzsche, Friedrich. 2003. Nietzsche: Writings from the Late Notebooks. Ed. Rüdiger Bittner. Trans. Kate Sturge. Cambridge University Press.

Plantinga, Alvin. 1967. God and Other Minds: A Study of the Rational Justification of Belief in God. Ithaca, NY: Cornell University Press.

1993. Warrant and Proper Function. New York, NY: Oxford University Press.

- 2000. Warranted Christian Belief. New York, NY: Oxford University Press.

- 2011. Where the Conflict Really Lies: Science, Religion, and Naturalism. Oxford University Press. 
Plantinga, Alvin, and Michael Tooley. 2008. Knowledge of God. Great Debates in Philosophy. Malden, MA: Blackwell Publishing.

Pyysiäinen, Ilkka. 2003. How Religion Works: Towards a New Cognitive Science of Religion. Leiden: Brill.

-2009. Supernatural Agents: Why We Believe in Souls, Gods, and Buddhas. New York: Oxford University Press.

Schjødt, Uffe, Andreas Roepstorff, Hans Stødkilde-Jørgensen, and Armin W. Geertz. 2009. "Highly religious participants recruit areas of social cognition in personal prayer." Social Cognitive and Affective Neuroscience 2: 199-207. 